\title{
WHY CRIMINAL RESPONSIBILITY FOR NEGLIGENCE CANNOT BE INDIRECT
}

\section{ALEXANDER GREENBERG ${ }^{1}$}

\begin{abstract}
A popular way to try to justify holding defendants criminally responsible for inadvertent negligence is via an indirect or "tracing" approach, i.e. an approach which traces the inadvertence back to prior culpable action. I argue that this indirect approach to criminal negligence fails because it cannot account for a key feature of how criminal negligence should be (and sometimes is) assessed. Specifically, it cannot account for why, when considering whether a defendant is negligent, what counts as a risk should be assessed relative to the defendant's evidence.
\end{abstract}

Keywords: criminal negligence, gross negligence manslaughter, culpability, tracing.

\section{INTRODUCTION}

How, if at all, are we justified in holding people criminally responsible for negligence? Criminal negligence is controversial because it involves an objective standard of culpability, and so allows for criminal responsibility when a defendant is unaware of the risks involved in what they are doing. Scepticism about criminal culpability that is not in some way tied to awareness has led many legal and moral philosophers to adopt an indirect "tracing" approach to inadvertent negligence, according to which the culpability in negligent defendants lies in their prior culpable actions which led them to be unaware of their risk-taking.

In this paper, I will argue that this indirect approach to criminal negligence fails. It fails because it cannot account for the fact that a defendant's negligence should be assessed relative to the evidence that defendant in fact possesses. This conception of criminal negligence, which I will call the "evidence-relative conception", has recently been adopted in English law, following two recent gross negligence manslaughter cases, $R . v$ Rudling and $R . v$ Rose. I will therefore use these two cases as a starting point to outline and defend the evidence-relative conception of criminal negligence.

My interest is not narrowly doctrinal, however. My argument is that by looking at these cases we can draw a more general philosophical conclusion about the structure of criminal negligence liability. Essentially, examining why an evidence-relative test for negligence is justified in these cases reveals that criminal negligence liability has a structure that cannot be explained by tracing it back to prior culpable action. This means that the indirect approach to criminal negligence fails. Culpability in criminal negligence is either direct or holding people criminally responsible for negligence is unjustified.

Furthermore, we should also draw a parallel conclusion about our moral responsibility for inadvertent culpable ignorance. Someone's moral responsibility for what they do unawares should also be assessed relative to their evidence, and this

\footnotetext{
${ }^{1}$ Leverhulme Early Career Fellow, Department of Philosophy, University College London. Address for Correspondence: Department of Philosophy, University College London, Gower Street, London, WC1E 6BT. Email: a.greenberg@ucl.ac.uk. For helpful comments on previous drafts, I am grateful to Lucy Campbell, David Campbell, Simon-Pierre Chevarie-Cossette, Claire Field, John Hyman, Max Kiener, Yuuki Ohta, Alexander Sarch, Findlay Stark, and two anonymous referees for the Cambridge Law Journal, as well as audiences at UCL and Lund. This work was supported by an Early Career Fellowship from the Leverhulme Trust (grant number: ECF-2019- 406).
} 
likewise cannot be accounted for by tracing approaches to culpable ignorance. Tracing thus cannot explain either criminal or moral responsibility for inadvertence.

\section{CRIMINAL NEGLIGENCE}

I will start by defining criminal negligence. Criminal negligence is a species of criminal culpability or fault. It is when criminal liability is imposed on the basis that a defendant should have been aware of some risk they are taking. A negligent defendant is one who causes harm when they should have been aware that their conduct carried the risk of harm, and should have taken precautions which, if taken, would have averted the harm.

Negligence is an "objective" standard of fault, in the sense that it does not require any mental states on the part of the defendant. In this respect, negligence differs from other mens rea concepts, such as intention, knowledge, and recklessness, which do refer to mental states and are in this respect "subjective". Recklessness as to a material element of an offence - e.g. recklessness as to whether someone else's property will be damaged - does require awareness that there is a risk of that element occurring. ${ }^{2}$

Most serious offences in English law require at least recklessness. For example, criminal damage, assault, and battery all require at least recklessness and cannot be committed negligently. ${ }^{3}$ More generally, it is a principle of statutory interpretation that if a statute defines an offence without requiring specific mens rea, there is a presumption that the offence requires at least recklessness. ${ }^{4}$ However, there are some important serious offences which can be committed negligently. The most prominent example is gross negligence manslaughter, which I will discuss below. Another example is the offence of causing or allowing a child or vulnerable adult to die or suffer serious physical harm, which requires that the defendant "was, or ought to have been, aware" of "a significant risk of serious physical harm being caused" to the victim. ${ }^{5}$ This is an offence of negligence because it allows for conviction on the basis that the defendant "ought to have been aware" of the relevant risk, even if they were not. A number of driving offences also involve objective tests of fault. Dangerous driving, for example, requires the defendant to drive in a way that "falls far below what would be expected of a competent and careful driver", and where "it would be obvious to a competent and careful driver that driving in that way would be dangerous". "Dangerous" here refers to

\footnotetext{
${ }^{2} R . v G$ and another [2003] UKHL 50, [2004] 1 A.C. 1034, 1057. Strictly speaking, the ruling in $G$ was only intended to cover the meaning of "recklessness" in relation to criminal damage (see Lord Bingham's comments at 1054). However, a number of judgments have not followed this restriction: see the cases noted in F. Stark, Culpable Carelessness: Recklessness and Negligence in the Criminal Law (Cambridge 2016), 27, note 6.

${ }^{3}$ For criminal damage, see the Criminal Damage Act 1971, ss. 1(1), 1(2)(a). For assault and battery (case law does not discriminate between these offences on mens rea issues), see R. v Spratt [1990] 1 W.L.R. 1073 (C.A.); $R v$ Savage \& R. v Parmenter [1992] 1 A.C. 699 (C.A.).

${ }^{4} B$ (a Minor) v DPP [2000] 2 A.C. 428, 462. Previous cases established the principle that there is a presumption of mens rea: see Sweet $v$ Parsley [1970] A.C. 132, 148. B added that this should be understood subjectively, i.e. as a presumption of at least recklessness. Not all common law systems read the presumption in this way. Some non-UK Commonwealth jurisdictions, such as Canada, Australia, and New Zealand, have a presumption that offences at least require negligence (by means of having a universally applicable "due diligence" defence). This alternative was discussed in Sweet v Parsley (at, e.g., 150, 157-158), but was not adopted, as the justices thought it to be inconsistent with the presumption of innocence established in Woolmington v DPP [1935] A.C. 462. For discussion, see A. P. Simester, J. R. Spencer, F. Stark, G. R. Sullivan, and G. J. Virgo, Simester and Sullivan's Criminal Law: Theory and Doctrine, 7th ed., (Oxford 2019), 213-15.

${ }^{5}$ Domestic Violence, Crime and Victims Act 2004, ss. (1)(c), (1)(d)(i).

${ }^{6}$ Road Traffic Act 1988, ss. 2A(1)(a)-(b).
} 
the danger of injuring people or seriously damaging property. ${ }^{7}$ We also find objective tests of fault in some sexual offences. Rape, for example, can be committed if the defendant "does not reasonably believe" that their sexual partner consents. ${ }^{8}$ The offence of sexual activity with a child can be committed if the defendant lacks a reasonable belief that their sexual partner is over $16 .{ }^{9}$ These are again objective tests because they mean one can be convicted even if one believes that one's sexual partner consents or if one believes that one's sexual partner is over 16 if such beliefs are not reasonable. For this reason - because they are offences for which criminal liability can be imposed on the basis of what the defendant should believe or what is reasonable for them to believe they are also offences which can be committed negligently.

A further wrinkle is that English law does not actually require negligence to be inadvertent, i.e. that the defendant is unaware of the relevant risk. All negligence requires is that a defendant fails to meet an objective standard, namely that they fail to take precautions against risk that a reasonable person would have. One can meet fail to meet this standard is if one is unaware of the relevant risk, but also if one is aware of the risk. ${ }^{10}$ However, to simplify things I am going to set this aside, and in what follows I will only consider cases of negligence in which the defendant is unaware of the relevant risk. This is fine for my purposes, because it is only in relation to inadvertent negligence that theorists feel the need to trace back to prior culpable action (typically because they are sceptical about culpability that is not in some way tied to awareness).

\section{DIRECT AND INDIRECT APPROACHES TO CRIMINAL NEGLIGENCE}

With criminal negligence defined, we can now distinguish between "direct" and "indirect" approaches to it. Both are attempts to justify criminal responsibility for negligence, i.e. they are putative explanations of when and why it is justified to hold people criminally responsible for inadvertent risk-taking. Both approaches assume that it is only justified to hold negligent defendants criminally responsible if such defendants display some kind of culpability or fault. But direct and indirect approaches give different answers to the question of where to locate the defendant's culpability.

The indirect approach, in the abstract, holds that the culpability in negligence is to be found by tracing back to prior culpable actions or omissions of the defendant's which led them to be unaware of the relevant risk. I will give more details below about what kinds of prior action we might point to, but the indirect approach's key claim is that we must trace the defendant's lack of awareness to some prior culpable action or omission if we are going to be justified in holding them criminally culpable for their inadvertent risk-taking. ${ }^{11}$ Furthermore, for reasons I will go into below, I am going to limit my attention to indirect approaches which require tracing the unawareness back to advertent culpable action, i.e. actions or omissions that are at least reckless as to the risk of one becoming unaware of the relevant risk.

\footnotetext{
${ }^{7}$ Ibid. section $2 \mathrm{~A}(3)$.

${ }^{8}$ Sexual Offences Act 2003, s. 1(1)(c).

${ }^{9}$ Ibid. section 9(c)(i). If the sexual partner is below the age of 13, however, the offence does not require a lack of reasonable belief; in such a case, liability is, in effect, strict with respect to age.

${ }^{10}$ See Simester et al., Simester and Sullivan's Criminal Law, 166-67.

${ }^{11}$ For versions of the indirect approach, see A. Kenny, Freewill and Responsibility (London 1978), 85; J. Hampton, "Mens Rea" (1990) 7 Social Philosophy and Policy 1, 10, 27-28; S. H. Pillsbury, "Crimes of Indifference" (1996) 49 Rutgers L.Rev. 105, 141-53.
} 
The indirect approach should be understood as the suggestion that criminal culpability for negligence should be understood as an application of more general principles of "prior fault". Prior fault is when one can be held criminally responsible for a later act when it results from earlier culpable conduct. ${ }^{12}$ Applications of principles of prior fault include, for example, rules governing defences, such as the rule that one cannot plead self-defence if one caused the assailant's attack, e.g., by taunting them. They also include the rule that lacking mens rea does not exculpate if it results from voluntary intoxication. ${ }^{13}$ According to the indirect approach, criminal culpability for negligence should be understood as of a piece with such rules. Doctrinally, negligence is not in fact treated as such, but this is by itself no objection to the indirect approach, which is an account of how we are justified in holding people criminally responsible for negligence. Defenders of the indirect approach can just claim that negligence standards should require prior fault and are unjustified insofar as they do not.

The direct approach to criminal negligence, by contrast, denies that the culpability in negligence needs to be traced back to any prior advertent culpable action or omission that led the defendant to be unaware of the relevant risk. The direct approach instead holds that a defendant's failure to be aware of a risk can itself be culpable. On this approach, one can be culpable, for example, for failing to pay enough attention to what one is doing, for failing to think before acting, or for forgetting something one needs to do. The direct approach claims that the culpability in criminal negligence is to be found in such cognitive failings on the part of the defendant, and denies that such cognitive failings need to be traced back to any prior culpable action. ${ }^{14}$

While my specific focus is on criminal negligence, this falls under the more general category of inadvertent culpable ignorance, and both direct and indirect approaches to culpable ignorance can be found in the moral responsibility literature. Many claim that ignorance can only be culpable if it is traced back to prior culpable action. ${ }^{15}$ On the other hand, many deny such tracing is required for ignorance to be culpable. Some, like the defenders of the direct approach to criminal negligence, claim that culpable ignorance is

\footnotetext{
${ }^{12}$ For general discussion, see P. Robinson, "Causing the Conditions of One's Own Defense: A Study in the Limits of Theory in Criminal Law Doctrine" (1985) 71 Virginia L.Rev. 1; C. Finkelstein, "Involuntary Crimes, Voluntarily Committed" in S. Shute and A. P. Simester (eds.), Criminal Law Theory: Doctrines of the General Part (Oxford 2002).

${ }^{13}$ DPP v Beard [1920] A.C. 479; DPP v Majewski [1977] A.C. 443. This only applies to offences of "basic intent", and not to those of "specific intent". Paradigmatic examples of crimes of specific intent are murder, wounding with intent, causing GBH with intent, theft, burglary, and handling stolen goods, and most other crimes are of basic intent. However, it is not clear what is supposed to mark the basic/specific intent distinction - for discussion, see D. Ormerod and K. Laird, Smith and Hogan's Criminal Law, 15th ed., (Oxford 2018), 318 22; Simester et al., Simester and Sullivan's Criminal Law, 743-46.

${ }^{14}$ H. L. A. Hart, Punishment and Responsibility: Essays in the Philosophy of Law, 2nd ed., (Oxford 2008), ch. 6; A. P. Simester, "Can Negligence Be Culpable?" in J. Horder (ed.), Oxford Essays in Jurisprudence, Fourth Series (Oxford 2000), 95-102; "A Disintegrated Theory of Culpability" in D. J. Baker and J. Horder (eds.), The Sanctity of Life: The Legacy of Glanville Williams (Cambridge 2013), 190-94; S. P. Garvey, "What's Wrong with Involuntary Manslaughter" (2006) 85 Texas Law Review 333, 363-82; V. Tadros, Criminal Responsibility (Oxford, 2005), ch. 9; Stark, Culpable Carelessness, ch. 8.

${ }^{15}$ H. M. Smith, "Culpable Ignorance" (1983) 92 The Philosophical Review 543, 563-66; M. J. Zimmerman, "Negligence and Moral Responsibility" (1986) 20 Noûs 199, 205-11; C. Ginet, "The Epistemic Requirements for Moral Responsibility" (2000) 14 Philosophical Perspectives 267, 273-75; G. Rosen, "Skepticism about Moral Responsibility" (2004) 18 Philosophical Perspectives 295, 300-04; J. M. Fischer and N. A. Tognazzini, "The Truth about Tracing" (2009) 43 Noûs 531; D. K. Nelkin and S. C. Rickless, "Moral Responsibility for Unwitting Omissions: A New Tracing View" in D. K. Nelkin and S. C. Rickless (eds.), The Ethics and Law of Omissions (Oxford 2017).
} 
grounded in agents' cognitive failings. ${ }^{16}$ Others, often known as "attributionists", deny both the need for tracing and the need to ground culpable ignorance in agents' cognitive failings, instead claiming that it suffices for ignorance to be culpable if it manifests an agent's ill will or lack of goodwill. ${ }^{17}$ If the argument of this paper is correct, it has implications for this debate, as parallel reasoning undermines an indirect approach to culpable ignorance. I will return to this question at the end of the paper.

Indirect approaches, both to criminal negligence and to culpable ignorance, are typically motivated by some form of scepticism about culpability that is not in some way tied to awareness. Such scepticism is typically based on two key claims. Firstly, it is claimed that cognitive states of awareness - and the lack of such states - are not chosen or under our control. Secondly, it is claimed that if a state of awareness - or lack of awareness - is not chosen or under our control, then it is an inappropriate basis for criminal responsibility. If these two claims are true, negligence starts to look like an inappropriate basis for culpability, given that it involves holding someone, who may be completely unaware of what they were doing, criminally responsible on the basis that they should have been aware of what they were doing. But if the relevant lack of awareness is traced back to prior culpable action, these sceptical worries go away.

I am not going to assess this argument here. I happen to think it fails, because I think it is false that we lack control, in whatever sense of control that is relevant to the criminal law, over what we are aware of. ${ }^{18}$ Nevertheless, proponents of indirect approaches to criminal negligence and culpable ignorance often defend their views by claiming that awareness is necessary for responsibility because it is necessary for control or choice. ${ }^{19}$

With the motivations of the indirect approach to criminal negligence on the table, I will now unpack the view in more detail. The central claim is that we are only justified in holding a defendant criminally responsible for negligence if we can trace their inadvertence to some prior culpable action. But what kind of action? In the abstract, we can define it as follows:

\footnotetext{
16 J. A. Montmarquet, "Culpable Ignorance and Excuses" (1995) 80 Philosophical Studies 41; G. Sher, Who Knew?: Responsibility Without Awareness (Oxford 2009), chs. 5-7; R. Clarke, Omissions: Agency, Metaphysics, and Responsibility (Oxford 2014), 166-67.

${ }^{17}$ E. Harman, "Does Moral Ignorance Exculpate?" (2011) 24 Ratio 443; M. Talbert, "Unwitting Wrongdoers and the Role of Moral Disagreement in Blame" in D. Shoemaker (ed.), Oxford Studies in Agency and Responsibility (Oxford 2013), 232-34; E. Mason, "Moral Ignorance and Blameworthiness" (2015) 172 Philosophical Studies 3037, 3040-46.

${ }^{18}$ A. Greenberg, "Epistemic Responsibility and Criminal Negligence" (2020) 14 Criminal Law and Philosophy 91, 97-103. For other defences of this claim, see Simester, "Can Negligence Be Culpable?", 95-102; “A Disintegrated Theory of Culpability", 190-93; Stark, Culpable Carelessness, 151-63, 232-36; M. Baron, "Negligence, Mens Rea, and What We Want the Element of Mens Rea to Provide" (2020) 14 Criminal Law and Philosophy 69, 77-79. I also think Hart can be interpreted as defending this claim, though he does not always put it in terms of "control": see Hart, Punishment and Responsibility, 149-52.

19 Hampton, "Mens Rea", 10-25; Pillsbury, "Crimes of Indifference", 123-28; Ginet, "The Epistemic Requirements for Moral Responsibility", 269; Nelkin and Rickless, "Moral Responsibility for Unwitting Omissions", 106-07, 120-28. An argument of this structure is also made by criminal negligence sceptics, who combine it with objections to tracing approaches, leaving scepticism the only option: see, in particular, L. Alexander and K. K. Ferzan, Crime and Culpability: A Theory of Criminal Law (Cambridge 2009), ch. 3. Some defenders of indirect approaches to culpable ignorance (e.g. Zimmerman, "Negligence and Moral Responsibility"; Rosen, "Skepticism about Moral Responsibility") claim it leads to a general scepticism about moral responsibility, so are also, a fortiori, sceptics about moral responsibility for negligence.
} 
A prior action or omission of D's, or a collection of such actions and omissions, which:

(a) Causes D to be unaware of the relevant risk, and:

(b) In relation to which $\mathrm{D}$ is at least reckless, i.e. $\mathrm{D}$ is at least aware of a risk that actions or omissions of that kind will lead them to be unaware of risks of the kind mentioned in (a).

Three quick clarifications are needed.

Firstly, the "relevant risk" in (a) will be the risk in relation to which the offence in question requires one to be negligent. For gross negligence manslaughter, this will be the risk of death; ${ }^{20}$ for rape, it will be the risk of not-consent, etc.

Secondly, I have assumed that the lack of awareness needs to be traced back to advertent culpable action, i.e. action that is at least reckless with respect to whether it will lead one to be unaware of the relevant risk. There are some proponents of tracing approaches who trace culpable inadvertence back to prior negligent actions. ${ }^{21}$ But such views do not seem well-motivated in this context, as they will not answer sceptical worries about the justifiability of criminal negligence liability. ${ }^{22}$

Thirdly, D's prior action is not reckless in the sense that D is aware of the risk mentioned in (a). For example, in a gross negligence manslaughter case, D's prior action would not reckless in the sense that they are aware of the risk of death. If that were the case, D would just be reckless and there would be no need for tracing. Rather, D's prior action is reckless in the sense that they are aware of the risk that they will be unaware of risks of the general kind mentioned in (a), e.g. in gross negligence manslaughter, they are aware of the risk that they will be unaware of a risk of death.

What examples of prior action or omission would fit this role? Now different proponents of the indirect approach give different examples. But we can sort possible awareness-influencing actions into (at least) four different categories if we build on a helpful categorisation scheme put forward by Rik Peels. ${ }^{23}$ And while this is a categorization scheme of different awareness-influencing actions, proponents of the indirect approach will have to mostly appeal to omissions to perform such actions, given that negligence involves the failure to be aware of the relevant risk.

Firstly, there are acts of gathering evidence. Examples might include carrying out internet research about symptoms or calling the doctor if one's child is sick, or looking to check there is no one on a street below before throwing down some building materials. By gathering such evidence, or by failing to gather it, one can influence what one is and is not aware of.

Secondly, there are actions through which we can influence our cognitive mechanisms. "Cognitive mechanisms' include our senses, such as sight, but also higherlevel capacities, such as one's reasoning ability and one's ability to interpret the evidence. One can take various steps to improve or hinder these mechanisms. One can improve one's eyesight by getting glasses and hinder it by failing to wear them. One can

\footnotetext{
${ }^{20}$ More specifically, for gross negligence manslaughter in English law this will be the serious risk of death. It is not entirely clear what "serious" is supposed to add, but I speculate below (see note 43).

${ }^{21}$ W. J. FitzPatrick, "Moral Responsibility and Normative Ignorance: Answering a New Skeptical Challenge" (2008) 118 Ethics 589, 601-08.

${ }^{22}$ For this criticism of FitzPatrick's negligence-based tracing view (ibid.), see Nelkin and Rickless, "Moral Responsibility for Unwitting Omissions", 115-16.

${ }^{23}$ R. Peels, Responsible Belief: A Theory in Ethics and Epistemology (Oxford 2017), 91-93.
} 
improve one's ability to interpret the evidence by engaging in education and research e.g. a doctor can improve their ability to assess evidence by taking specialist courses and reading up on new diagnostic research and guidance. And one can hinder one's ability to interpret the evidence by failing to take such steps.

Thirdly, there are actions by which we can inculcate epistemic virtues and eliminate epistemic vices in ourselves. Epistemic virtues and vices are kinds of cognitive disposition. Epistemic virtues include, to use Peels' helpful list, "open-mindedness, intellectual courage, carefulness, precision, diligence, and thoroughness". ${ }^{24}$ Epistemic vices include traits like gullibility, dogmatism, dismissiveness, close-mindedness, and prejudice. And just as with cognitive mechanisms, we can take some steps to inculcate epistemic virtues and eliminate epistemic vices. One can try to reduce one's gullibility, for example, by trying to train oneself to not be so credulous when faced with testimony appearing to confirm what one wants to be the case. And insofar as we can take steps to inculcate epistemic virtue or avoid epistemic vices, we can also influence what we are and are not aware of.

Note here that the indirect approach need not involve the clearly false claim that the workings of our cognitive mechanisms or our epistemic virtues and vices are entirely the product of deliberate action. It only needs the claim that there are some actions we can take which affect these features of ourselves, and thus affect what we are and are not aware of.

Fourthly, and finally, there are various mental actions through which we can influence what we aware of. Examples might include engaging in self-conscious reflection, mulling something over, directing one's attention, or concentrating on what one needs to do. And even if we do lack control or choice over awareness itself, we clearly do have control and choice over whether we engage in reflection, over what we mull over, and over where we pay attention. And such mental acts clearly influence what we are aware of. Therefore, such mental actions are another way in which we can indirectly influence what we are and are not aware of. ${ }^{25}$

There are at least these four categories of awareness-influencing actions. With this in mind, the indirect approach to criminal negligence can be understood as the claim that we are only justified in holding a defendant responsible for inadvertent risk-taking if a) their lack of awareness results from an action or omission of one of these kinds, or a collection of such actions or omissions, and b) they are reckless as to whether that action or omission could lead them to be unaware of the relevant risk.

Let us illustrate with one of the offences I have already mentioned: causing or allowing a child or vulnerable adult to die or suffer serious physical harm. Let us say that a child has a medical condition which goes untreated, leading to the child's death, and the child's parents let this happen because they were unaware of the risk to the child's health. According to the indirect approach, we are only justified in holding the parent's criminally responsible if we can trace the parents' lack of awareness of the risk to their child's health back to some prior culpable action or omission.

What kind of action or omission could this be? It could be a failure to gather evidence, such as failing to research symptoms or failing to make inquiries with a doctor. It could be an action or omission which influenced their cognitive mechanisms in such a

\footnotetext{
${ }^{24}$ Peels, Responsible Belief, 92.

${ }^{25}$ This fourth category is my own addition. Mental actions, in particular, acts of perceptual attention, play a central role in Pillsbury's indirect approach to negligence: see "Crimes of Indifference", 143-44.
} 
way that led them to be unaware of the risk to their child's health, e.g. they could have been intoxicated through drink or drugs, or they could have failed to study parenting advice about how to assess symptoms of serious illness. It could be an action or omission which led to or sustained some epistemic vice. For example, they could have not taken steps to remedy their overly suspicious attitude towards authority, which led them to be too credulous in response to each other's assurance that their child was "probably fine" and did not need to see the doctor. It could have been a failure to perform some mental action, such as a failure to direct their attention sufficiently towards their child's symptoms. According to the indirect approach, we are only justified in holding the parents criminally responsible for the child's death if the parents a) performed some action or omission like this, and b) they were aware these actions created a risk they would be unaware of risks to their child's health.

That suffices to outline the indirect approach to criminal negligence. In the remainder of this article, I will argue we should reject it. In brief, I will argue that we should understand criminal negligence in an evidence-relative manner. According to such an understanding, when we are assessing whether D was negligent, what counts as a risk is to be assessed relative to D's evidence. I will then go on to show that the indirect approach to negligence cannot explain this. Essentially, this is because the evidencerelative conception of negligence requires that one way of influencing what we are aware of - gathering evidence - is not to be considered when assessing a defendant's negligence. But the indirect approach cannot explain this restriction, because gathering evidence just is one way of influencing awareness among others. So the indirect approach to criminal negligence should be rejected.

At this point, it is worth noting how the objection I will develop to the indirect approach to criminal negligence is distinct from other objections made in the literature. The typical objection to indirect approaches to negligence involves putting forward putative cases of culpable negligence which cannot be traced back to any prior culpable action. ${ }^{26}$ While my objection might superficially resemble this typical objection, it is in fact quite different. The typical objection claims that tracing is not sufficient to explain all instances of culpable negligence. The claim that tracing can explain some instances of culpable negligence is either conceded (often implicitly) or granted for the sake of argument, as evidenced by the literature often distinguishing between "tracing cases" and "non-tracing cases" of negligence and culpable ignorance. ${ }^{27}$ My objection is that tracing is not sufficient to explain any instance of culpable negligence, because it cannot explain why our negligence assessments quite generally should be evidence-relative. If I am right, no case of culpable negligence should be thought of as a "tracing case", if by this we mean a case of culpable negligence that can be explained by tracing alone. My objection thus provides a reason to reject the indirect approach root and branch in a way that the typical objection does not.

\footnotetext{
${ }^{26}$ See, e.g., S. Sverdlik, "Pure Negligence" (1993) 30 American Philosophical Quarterly 137, 139-41; M. Vargas, "The Trouble with Tracing" (2005) 29 Midwest Studies in Philosophy 269; M. King, "The Problem with Negligence" (2009) 35 Social Theory and Practice 577, 578-82; Sher, Who Knew?, 34-39; M. S. Moore and H. M. Hurd, "Punishing the Awkward, the Stupid, the Weak, and the Selfish: The Culpability of Negligence" (2011) 5 Criminal Law and Philosophy 147, 176-82; Clarke, Omissions, 108-10, 164-74.

${ }^{27}$ See, e.g., Holly M. Smith's two papers, "Non-Tracing Cases of Culpable Ignorance” (2011) 5 Criminal Law and Philosophy 115; "Tracing Cases of Culpable Ignorance" in R. Peels (ed.), Perspectives on Ignorance from Moral and Social Philosophy (London 2017).
} 


\section{THE EVIDENCE-RELATIVE CONCEPTION OF CRIMINAL NEGLIGENCE}

What I am calling an "evidence-relative" conception of criminal negligence has recently been recognised in English law, following two recent gross negligence manslaughter decisions, $R . v$ Rudling ${ }^{28}$ and $R . v$ Rose.${ }^{29}$ The evidence-relative conception resulted from the clarification of one of the requirements of gross negligence manslaughter. Gross negligence manslaughter, roughly, is negligently causing the death of someone to whom one owes a duty of care. In addition, the negligence involved must be extreme (i.e. "gross"). More formally, it has five requirements, summarised in Rose: ${ }^{30}$

(a) the defendant owed an existing duty of care to the victim;

(b) the defendant negligently breached that duty of care;

(c) it was reasonably foreseeable that the breach of that duty gave rise to a serious and obvious risk of death;

(d) the breach of that duty caused the death of the victim;

(e) the circumstances of the breach were truly exceptionally bad and so reprehensible as to justify the conclusion that it amounted to gross negligence and required criminal sanction.

Rudling and Rose concerned the interpretation of requirement (c). This requirement involves an objective test, in that a "reasonably foreseeable" risk is understood as a risk a reasonable person would foresee, whether or not the defendant did in fact foresee it. And, while remaining objective, if the defendant has specialist knowledge, the test takes that into account. If the defendant is a doctor, the test asks whether a reasonable doctor would have foreseen the risk. ${ }^{31}$

Rudling and Rose added the clarification that whether a serious and obvious risk of death was reasonably foreseeable should be assessed relative to the defendant's knowledge at the time of the duty breach. ${ }^{32}$ Now the courts speak of "knowledge" rather than "evidence", but we can also think of this as a test of reasonable foreseeability that is relative to the evidence a defendant possesses if we hold that the evidence one possesses consists in the propositions or facts one knows. ${ }^{33}$ Now speaking of a "defendant's evidence" can be somewhat ambiguous, as it could also be understood as referring to evidence that is easily available to a defendant. But as I use it, I mean to refer to evidence actually possessed by a defendant, understanding this possession in terms of knowledge.

The clarification made in Rudling and Rose matters because it highlights something underdetermined by the notion of a risk that a reasonable person - or a reasonable doctor - would foresee. What if our doctor failed to carry out investigations that a reasonable doctor would have? Do we count the evidence the reasonable doctor would have when considering whether a reasonable doctor would have foreseen a risk of death? Rudling and Rose say "no".

\footnotetext{
28 [2016] EWCA Crim 741, (2016) 151 B.M.L.R. 79.

${ }^{29}$ [2017] EWCA Crim 1168, [2018] Q.B. 328.

${ }^{30}$ Ibid., 349. The gross negligence manslaughter test originates in R. v Bateman (1925) 19 Cr. App. R. 8 and was reaffirmed in R. v Adomako [1994] UKHL 6, [1995] 1 A.C. 171.

${ }^{31}$ Adomako [1994] UKHL 6, 188.

32 The requirement of a "serious and obvious risk of death" has its roots in $R$. v Singh [1999] Crim. L.R. 582, and was approved in R. v Misra [2004] EWCA Crim 2375, [2005] 1 Cr. App. R. 21, at [66].

${ }^{33}$ For this view, see T. Williamson, "Knowledge as Evidence" (1997) 106 Mind 717.
} 
In Rudling, D was a GP. A patient of hers, a thirteen-year-old boy died of Addison's syndrome, a rare auto-immune disease, the early symptoms of which are nonspecific (fatigue, weakness, vomiting). When symptoms worsened severely, the patient's mother spoke to D about the symptoms over the phone (on a Friday), and D advised her to bring her son into the GP's surgery the following Monday. The patient died on Saturday morning. The prosecution alleged that, given the symptoms, D should have carried out a home visit to examine the patient in person, and if she had it would have been obvious that his condition was life-threatening and he was in urgent need of care.

In Rose, D was an optometrist who was carrying out a routine eye examination on a patient, a seven-year-old boy. D failed to examine the patient's optic nerve with an ophthalmoscope, which she had a statutory duty to do, claiming the patient was uncooperative. If D had carried out the examination, it would have been apparent that there was a risk of papilloedema (the swelling of the optic nerve) a life-threatening condition associated with hydrocephalus. Retinal images taken from the patient also showed indications of papilloedema, but D claimed that she had not viewed them and that it was likely that she was shown retinal images from another patient by mistake. The patient died six months later from hydrocephalus, which could have been treated if the patient were referred to a specialist at the time of the examination.

Both of these cases involved medical professionals who lacked evidence because they failed to carry out certain investigations. In both cases, the prosecution alleged that the defendant, in failing to carry out those investigations, negligently breached a duty of care. The Court of Appeal held that neither case amounted to gross negligence manslaughter even if there was the alleged duty breach, on the grounds that "the question of whether there had been a serious and obvious risk of death had to be assessed with respect to knowledge at the time of the breach of duty". ${ }^{34}$ And this means, the court concluded, that "it is not appropriate to take into account what the defendant would have known but for his or her breach of duty." 35 Given this understanding of the test, whether it was reasonably foreseeable that there was a serious and obvious risk of needs to be assessed relative to Rudling's knowledge at the point of the Friday phone call, given she had not visited the patient, and relative to Rose's knowledge gained through the incomplete eye-examination during which she failed to examine the optic nerve. And assessed from these perspectives, the court held that a serious and obvious risk of death was not reasonably foreseeable in either case. ${ }^{36}$

This is what I have been calling an "evidence-relative" conception of criminal negligence, because it involves a test of reasonable foreseeability which only takes into account the evidence the defendant in fact possesses; a non-evidence-relative test would take into account all the evidence the reasonable person would have, regardless of whether that evidence is in fact possessed by the defendant. In the next section, I will argue that English law is correct on this front: we should favour an evidence-relative conception of criminal negligence. In making this argument, I will restrict my discussion to gross negligence manslaughter. However, the reasons for preferring an evidencerelative test of reasonable foreseeability also apply to other offences which feature objective tests of fault. In section 6, I will then argue that the fact that criminal negligence

\footnotetext{
${ }^{34}$ Rose, [2018] Q.B. 328, 328; see also 349.

${ }^{35}$ Ibid., 354.

${ }^{36}$ Ibid., 351-2; Rudling, at [39]-[42].
} 
assessments should be evidence-relative undermines the indirect approach to criminal negligence, because the indirect approach cannot account for this fact.

\section{IN DEFENCE OF THE EVIDENCE-RELATIVE CONCEPTION}

There are two main reasons to prefer the evidence-relative conception of criminal negligence, which I will now outline. I will also answer some objections to the evidencerelative test of reasonable foreseeability given by Karl Laird. ${ }^{37}$

The first reason to prefer the evidence-relative conception is that a non-evidencerelative conception is apt to result in a mismatch between the defendant's degree of culpability and the severity of the offence they are convicted of. This kind of mismatch is evident in the two cases we have been focusing on. If the defendants in Rudling and Rose did indeed negligently breach their duties of care in, respectively, failing to carry out a home visit, and failing to examine the optic nerve, then it is plausible they had some degree of culpability or fault. But it does not look like an appropriate degree of culpability for manslaughter. More abstractly, it is clearly possible that one can be guilty of a failure to gather evidence, where one is culpable to a relatively minor degree, but where it would be a more egregious error to fail to recognize what that evidence indicates. This is possible just because dangers can be opaque to us. So given that such cases are possible, a non-evidence-relative test of reasonable foreseeability is apt to result in a mismatch between the defendant's culpability and the severity of the offence for which they are convicted.

Since this argument appeals to the "severity" of an offence like manslaughter, one may ask how this is measured. This is especially apposite with offences, like manslaughter, which covers a range of cases of varying severity, differences which may be accounted for in sentencing. While I think it is intuitive that manslaughter is less serious than, e.g., murder and more serious than criminal damage, I am not going to try to give a complete theory of what makes offences more or less serious. All I need to say to defend my argument is that manslaughter is an offence which gets its seriousness, at least in large part, from its results - i.e. the victim's death - and that the defendant is culpably linked to that death via their failure to be aware of the risk of death.

This is all I need to defend the claim that a non-evidence-relative test of reasonable foreseeability, which allows in failures of evidence gathering, will lead to mismatches between a defendant's degree of culpability and the severity of the offence. This is because the offence gets its seriousness from something - the victim's death - the risk of which may only be obvious if the defendant had more evidence (and also because failures of evidence gathering can often be relatively minor). So given that manslaughter gets its seriousness from results, even if we do not have a full theory of what makes offences more or less serious, we can still be confident that a non-evidence-relative conception of negligence will lead to a mismatch between the defendant's culpability and the severity of the offence they are held responsible for.

The fact that there is the potential for this kind of mismatch if the test for reasonable foreseeability is not restricted to the defendant's evidence was something that worried the court in Rose, and was mentioned by Sir Brian Leveson P in his concluding remarks:

\footnotetext{
${ }^{37}$ K. Laird, "The Evolution of Gross Negligence Manslaughter" (2018) 1 Arch. Rev. 6; "R. v Rose (Case Comment)" (2018) Crim. L.R. 76.
} 
The implications for medical and other professions would be serious because people would be guilty of gross negligence manslaughter by reason of negligent omissions to carry out routine eye, blood and other tests which in fact would have revealed fatal conditions notwithstanding that the circumstances were such that it was not reasonably foreseeable that failure to carry out such tests would carry an obvious and serious risk of death. ${ }^{38}$

This concern strikes me as entirely correct. Given risks can be opaque to us, minor negligent failures of evidence gathering might mean defendants lack what would be clear evidence of risk. Assessing such defendants on the basis of such evidence will lead, in many cases, to a mismatch between the degree of culpability and the severity of the offence they are held responsible for.

Laird has objected that the court's concerns overstate the effects a non-evidencerelative test of reasonable foreseeability would have on medical professionals. He points out that failures to carry out the routine tests often will not be negligent, even if they in fact lead to failures of diagnosis. On this basis, Laird claims that the court "assumed that such omissions [to carry out routine tests] are negligent, but this will not necessarily be the case". ${ }^{39}$ A non-evidence-relative test which only considered evidence defendants lacked because of negligent omissions would not, Laird suggests, have the effects the court worried about.

I do not think Laird's objection really targets the court's concerns, at least if I am right that what's driving them. The worry is that a failure to gather evidence - even if it is negligent - can and often will only be culpable to a minor degree, and to a degree for which a manslaughter conviction is out of proportion. Laird's point that not all failures of diagnosis are negligent, while correct, does not answer that.

There is a possible response Laird could give here. He could appeal to the final, "grossness" requirement of gross negligence manslaughter, i.e. that "the circumstances of the breach were truly exceptionally bad and so reprehensible as to justify the conclusion that it amounted to gross negligence and required criminal sanction". He could claim not just any negligent failure of evidence gathering will suffice, but only one which is grossly negligent. This might be thought to avoid the possibility of the kind of mismatch which I have claimed a non-evidence-relative test creates.

But this response does not work, for both practical and philosophical reasons. Practically, it seems unwise to allow the grossness requirement to shoulder the burden of determining when a failure of evidence gathering is sufficiently serious, given that it is stated in open-ended evaluative language ("truly exceptionally bad"), and looks like it is either circular or asks juries to answer a question of law. ${ }^{40}$

Philosophically, this move does not really deal with the issue of mismatch I have been raising. Insofar as the grossness requirement is informative, it is a requirement that the defendant's conduct fell far below the standard we would expect from a reasonable person or from a reasonable professional in the defendant's field. Now it is clearly

\footnotetext{
${ }^{38}$ Rose [2018] Q.B. 328, 354.

${ }^{39}$ Laird, "The Evolution of Gross Negligence Manslaughter", 9.

${ }^{40}$ For this criticism, see Law Commission, Legislating the Criminal Code: Involuntary Manslaughter (Law Com. No. 237, 1996), at [3.9]. This criticism has, however, been rejected by the Court of Appeal: see Misra [2004] EWCA Crim 2375, at [58]-[62]. Nevertheless, it is not clear the court's response is convincing (see, e.g., Ormerod and Laird, Smith and Hogan's Criminal Law, 594), and we should, at the very least, avoid giving too great an explanatory role to the grossness requirement.
} 
possible that a doctor could be guilty of a failure of evidence gathering which was grossly negligent in this sense, but where there is still a mismatch. Say a doctor sees a patient complaining of some mild symptoms, and the doctor fails to take the most elementary precaution of carrying out blood tests. If the doctor did, however, the blood tests would show a very rare condition, a condition which is treatable but fatal if untreated. In such a case, the doctor's failure to carry out the tests looks grossly negligent - it fell far below the standard of a reasonable doctor - but nevertheless there is still a mismatch between the culpability and the severity of the offence. Given the rarity of the condition, it is out of proportion to hold the doctor criminally responsible for manslaughter. ${ }^{41}$ And this case, again, just trades on the fact that risks can be opaque to us.

For this reason, we should prefer an evidence-relative test of reasonable foreseeability, because it removes the possibility for this kind of mismatch. This is not to say the evidence-relative conception of negligence rules out all possible mismatches between the defendant's culpability and the severity of the offence they are held responsible for. For instance, if the test of reasonable foreseeability is not relativized to the defendant's incapacities - e.g. if it does not cater to defendants with substandard intelligence and other cognitive shortcomings - then it will plausibly still lead to some mismatches. ${ }^{42}$ My claim is just that an evidence-relative test will not lead to the kind of mismatches a non-evidence-relative test does.

The second reason to prefer the evidence-relative conception of negligence, which may be related to the first, relates to the wording of the test of reasonable foreseeability for gross negligence manslaughter. That test requires that "it was reasonably foreseeable that the breach of that duty gave rise to a serious and obvious risk of death". What I want to focus on is the requirement that the risk is obvious. Obviousness is an epistemic concept, and one that is relative to one's evidence. Something can be obvious to me but not to you because I have evidence you lack. If we think about why we care about the obviousness of risk when assessing criminal negligence, it becomes clear that we should care about what is obvious given the defendant's evidence, and not what is obvious given the evidence a reasonable person would have.

Why do we care, when assessing criminal negligence, that the risk is obvious rather than just serious? ${ }^{43}$ It is plausible that we care about obviousness of risk in order to get the right kind of connection between the risk and the person in order to justify holding the person criminally responsible for taking the risk. We can think of this as an instance of what A.P. Simester calls "the basic challenge of culpability". ${ }^{44}$ This challenge is raised

\footnotetext{
${ }^{41}$ In addition, such a doctor is not plausibly grossly negligent in relation to their patient's death, which is required for gross negligence manslaughter, a point I will return to below.

${ }^{42}$ I should note that worries about a capacity-relative negligence standard do not apply to an evidence-relative one. For example, some have worried that a standard relative to all the defendant's shortcomings ceases to be an objective standard (see, e.g., Ormerod and Laird, Smith and Hogan's Criminal Law, 136-38; cf. T. Honoré, Responsibility and Fault (Oxford 1999), 33-34; for a response, see Simester et al., Simester and Sullivan's Criminal Law, 169-74). One also might have a more practical worry that it is difficult to know whether or not someone had the capacity to recognise risk. Neither worry applies to an evidence-relative test. An evidencerelative test is clearly still objective. And given we are assuming that a fact is in one's evidence if one knows it, one can know a defendant's evidence if one knows what they know, something the criminal law accepts can be proven in other contexts.

${ }^{43}$ The courts have not defined what "serious" is supposed to mean, and how it is distinct from "obvious". But it is natural to read "serious" as denoting that the risk is above a certain threshold of likelihood in some objective but non-evidence-relative sense of probability. To illustrate, Marie Curie's exposure to radiation created a serious risk to her health and her life, but one that was not obvious given what was known at the time.

${ }^{44}$ Simester, "A Disintegrated Theory of Culpability", 179.
} 
by the fact that culpability requires more than just a bad act. We need, as Simester puts it, "to trace our negative evaluation of $\varphi$ ing back to D, the person who does it", and justify the "evaluative link between act and defendant - that link which allows us to transmit judgments of the deed across to the person". ${ }^{45}$

Obviousness of risk helps answer this challenge because it connects the risk to the person in the right kind of way, i.e. it explains why the badness of the risk-taking speaks badly of the person who takes the risk. Obviousness does this because risks that are just serious - and not obvious - might not speak badly of the person who takes them. We can see this by looking at unforeseeable serious risks. Consider, for example, a doctor who prescribes some medicine which causes a life-threatening allergic reaction in their patient, but an allergic reaction they had no reason to suspect would occur when they prescribed the medicine. In prescribing the medicine, the doctor takes a serious risk, but that risk does not speak badly of him, plausibly because the risk was not obvious.

Now if we care about the obviousness of risk for this reason - because it explains why the badness of the risk-taking speaks badly of the defendant - then should we care about whether the risk was obvious given the evidence the defendant in fact had? Or should we care about whether the risk would be obvious given the evidence a reasonable person would have had, but which the defendant may lack? The former option looks much more plausible. The latter option - of focusing on what would be obvious given the evidence of a hypothetical reasonable person - does not provide a plausible explanation of why the badness of risk-taking speaks badly of the person who takes it. This is because the defendant may lack some evidence of serious risk because of a relatively minor failure of evidence gathering, as was the case in Rudling and Rose. The risks the defendants took in these cases may speak badly of them to some degree. But given the evidence the defendants lacked, there does not seem to be the right kind of connection between the risk of death and the defendants for that risk to speak badly of them. So it is inappropriate to hold such defendants criminally responsible for causing the risk of death. Therefore, the reason why we care about the obviousness of risk when assessing criminal negligence favours the evidence-relative conception.

Those are the two reasons why we should favour the evidence-relative conception of negligence. As I mentioned in passing, they may well be related. The first reason to favour an evidence-relative conception of criminal negligence was that a non-evidencerelative conception is apt to lead to mismatches between a defendant's culpability and the severity of the offence they are convicted of in cases where risks are opaque to the defendant. The second reason I have given plausibly explains why cases of opaque risks lead to such mismatches. They do so because when it is opaque to you that you are taking a risk, there is not the right connection between you and the risk you are taking for it to speak badly of you. This will clearly be the case if the offence gets its seriousness from something - such as the victim's death in manslaughter - the risk of which would only be obvious to you if you had more evidence.

I will now move on to consider two further objections Laird raises against the evidence-relative test of reasonable foreseeability. Laird's first objection is that the decision in Rose means, paradoxically, that one escapes liability for more serious breaches of one's duty of care:

\footnotetext{
${ }^{45}$ Ibid., 179-80.
} 
As a result of the court's analysis in Rose, the more egregious the defendant's breach of duty, the less likely it is that he or she will be guilty of gross negligence manslaughter. To put the point another way, the optometrist who carries out an examination of the internal eye, but fails to perceive the obvious symptoms of hydrocephalus may be guilty, but the optometrist who fails even to attempt an examination of the internal eye will not commit the offence. All things being equal, surely the latter is more culpable than the former? ${ }^{46}$

Laird's suggestion - that an optometrist who fails to carry out a test is more culpable, all else equal, than one who fails to recognise what a test indicates - has an initial ring of plausibility. But on further examination, it does not seem to be true. Whether such an optometrist is more culpable looks like it varies depending on further features of the case in question. Crucially, it varies depending on the strength of evidence that would result from the test. In a case in which a defendant, because of a relatively minor failure of evidence gathering, lacks evidence which would clearly indicate a risk of death - as was the case in Rose - then it is not clear that the optometrist who failed to carry out the test would be more culpable. On the other hand, in a case in which the test would not result in clear evidence of a risk of death, it is definitely possible that the defendant who fails to carry out the test is more culpable. But this does not support Laird's objection, for a couple of reasons. Firstly, it would just be one case in which failing to carry out a test would be more culpable. It does not establish the general claim that failing to carry out a test is more culpable, all else equal, than failing to recognise what a test indicates. Secondly, in the latter kind of case neither optometrist would be guilty of gross negligence manslaughter because for neither of them would there have been a serious and obvious risk of death.

Furthermore, even if we grant that Laird is correct that someone who fails to carry out a test is more culpable, we still have to ask if they are more culpable with respect to causing death (assuming, as in Rose, the failure to carry out the test causes the patient's death). The optometrist who fails to carry out the test may well be more culpable with respect to carrying out their professional duties and may well be a worse optometrist. But it is a distinct question whether they are more culpable with regards to causing death, and it is only culpability with regards to causing death which is relevant if this culpability is supposed to ground a gross negligence manslaughter conviction. And it is not plausible that the optometrist who fails to carry out the test is more culpable with regards to causing death, if the risk of death was in no way obvious prior to carrying out the test.

Laird's second objection is that the evidence-relative conception creates "a perverse incentive for those who owe a duty of care to another to do as little as possible to discharge it and in so doing avoid potential criminal liability", and suggests that "it is not inconceivable that a landlord might decide not to provide his tenants with a carbon monoxide detector so that he remains ignorant should gas ever leak from the boiler". ${ }^{47}$

This issue of perverse incentives has, in my view, been convincingly answered by Findlay Stark, who gives three possible replies. ${ }^{48}$ Firstly, perverse incentives can plausibly be eliminated by means other than the prospect of a gross negligence

\footnotetext{
${ }^{46}$ Laird, "The Evolution of Gross Negligence Manslaughter", 8; also see Laird, " $R$. v Rose (Case Comment)", $79-81$.

${ }^{47}$ Ibid., 8-9.

${ }^{48}$ F. Stark, "In Praise of Rose" (2019) Arch. Rev. 7, 9.
} 
manslaughter conviction, such as regulatory measures or civil liability. Secondly, there is the possibility of creating specific criminal offences relating to particular failures of investigation as alternatives to manslaughter. Thirdly, Laird's landlord looks like he is wilfully blind - i.e. someone who deliberately refrains from investigating in order to remain ignorant - which means that he would not escape liability even given the test put forward in Rose.

It is worth briefly unpacking this third response, as the possibility of wilful blindness playing this role was hinted at in Rose, ${ }^{49}$ and explicitly recognised in the subsequent case of $R . v$ Winterton. ${ }^{50}$ The doctrine of wilful blindness holds that a defendant can be treated as if he knew that something is the case if he "deliberately shut his eyes to the obvious or refrained from enquiry because he suspected the truth but did not have his suspicions confirmed". ${ }^{51}$ Appeals to wilful blindness typically occur when knowledge is the requisite mens rea for an offence, but the court in Rose and Winterton recognised that this rule could also be applied to a defendant's knowledge in relation to the test of reasonable foreseeability in gross negligence manslaughter. In other words, whether a risk was reasonably foreseeable should not just be assessed given the facts the defendant knows, but also the facts they are wilfully blind to; such facts should be treated as among the defendant's possessed evidence, as I have been putting it. If we apply this to Laird's landlord who decides "not to provide his tenants with a carbon monoxide detector so that he remains ignorant should gas ever leak from the boiler", such a person plausibly meets the conditions for being wilfully blind to the fact that there is a gas leak, so can count as knowing this. For such a defendant, we can then ask, given that there was a carbon monoxide leak, was a serious and obvious risk of death reasonably foreseeable, to which the answer would probably be "yes".

I should also note that allowing in evidence the defendant is wilfully blind to is consistent with reasons I have given to prefer the evidence-relative view. I firstly suggested that considering all the evidence the reasonable person would have creates the possibility for mismatches between the defendant's degree of culpability and the severity of the offence we hold them responsible for. The same is not the case if we include evidence the defendant is wilfully blind to, at least if the wilful blindness doctrine justified more generally. ${ }^{52}$ If the wilful blindness doctrine is justified, being wilfully blind to evidence that indicates a serious and obvious risk of death involves greater culpability than lacking evidence merely because one negligently breached a duty of care. Secondly, I argued that a non-evidence-relative test of reasonable foreseeability does not establish the requisite connection between the risk and the defendant to explain why the badness of the risk-taking speaks badly of them. There is not the same issue with including evidence the defendant is wilfully blind to. This is because a wilfully blind defendant's suspicion of the relevant fact (e.g. the landlord's suspicion of a gas leak), along with their deliberately remaining ignorant, connects them to the risk in a way that explains why the badness of the risk speaks badly of the defendant. We should, therefore, favour a test of reasonable foreseeability which is relative to the evidence possessed by the defendant and evidence they are wilfully blind to.

\footnotetext{
${ }^{49}$ Rose [2018] Q.B. 328, 353.

${ }^{50}$ [2018] EWCA Crim 2435, [2019] Crim. L.R. 336, at [27].

${ }^{51}$ Westminster City Council v Croyalgrange Ltd [1986] 1 W.L.R. 674, 684.

${ }^{52}$ For discussion of how to justify the doctrine, see A. Sarch, Criminally Ignorant: Why the Law Pretends We Know What We Don't (Oxford 2019), chs. 3-4.
} 
Now I have argued this in relation to the test of reasonable foreseeability in gross negligence manslaughter. But the reasons for favouring it in that case apply more generally to other instances of criminal negligence. ${ }^{53}$ The first reason, again, was that a non-evidence-relative negligence standard leads to mismatches between the defendant's degree of culpability and the severity of the offence they are responsible for. This is also true in relation to other offences.

To show this it will be helpful to return to what I said above about what makes manslaughter as serious an offence as it is. I said that manslaughter gets its severity, in large part, from results, i.e. the victim's death. And because a risk of death can be opaque to one, one can lack what would be obvious evidence of a risk of death through a relatively minor failure of evidence gathering. This means that an evidence-relative test is apt to lead to manslaughter convictions where there does not look like there is culpability sufficient for such a serious offence as manslaughter.

Parallel reasoning also applies to other offences of negligence. Some other offences of negligence do not get their seriousness from results, but from other features about which we can say much the same. Some get their severity from circumstances, such as sexual offences like rape or sexual activity with a child, which are wrongs because of circumstances, i.e. the lack of consent or the victim's age. Others, such as dangerous driving, get their severity from the mere fact that they create the risk of some results. The wrong in the offence of dangerous driving seems to be just that one's driving creates a danger of injuring people or seriously damaging property. ${ }^{54}$ But with each offence, when committed negligently, the defendant is culpably linked to these results or circumstances by a failure to be aware of a risk of them; or, with dangerous driving, they are culpably linked to a risk by a failure to be aware of it. This means that a non-evidence-relative negligence standard will is apt to lead to mismatches in these cases too. This is because the different offences get their seriousness from some feature, the risk of which may only be obvious if the defendant had more evidence, evidence the defendant may lack because of a relatively minor failure of evidence gathering. This means that we can expect a nonevidence-relative conception of negligence to create the kind of mismatches I have been highlighting quite generally.

The second reason I gave in favour of the evidence-relative conception of negligence was that that a non-evidence-relative test of reasonable foreseeability does not establish the requisite connection between the risk and the defendant to explain why the badness of the risk-taking speaks badly of them. This also applies to other offences of negligence. A non-evidence-relative test did not establish the requisite connection between the defendant and the risk because risks can be opaque to us and a serious risk may not speak badly of a person if it is not obvious given their evidence. And all kinds of risk can be opaque to us, not just risks of death. So this second reason also applies not just to manslaughter, but more generally to other offences of negligence.

We can make these points less abstract by illustrating how cases of the structure of Rose and Rudling can occur in relation to another offence of negligence, dangerous driving. Let us say that a student is sleeping underneath your car after a very heavy night out. Incidentally, your tyres are grossly underinflated; underinflated to such a degree that

\footnotetext{
${ }^{53}$ I do not think the same considerations will apply to negligence in tort, as a tort liability does not require the same kind of culpability or fault.

${ }^{54}$ The offence does not require that anyone actually be injured or any property actually be damaged. See the Road Traffic Act ss. 2A(1)-(3).
} 
driving with such tyres plausibly falls far below what is expected of a careful and competent driver, and it would obvious to a careful and competent driver that such tyres need to be inflated. If you had pumped the tyres up, you would have noticed the sleeping student, but you are in a rush so do not inflate them. You start the car and drive off, narrowly missing the sleeping student. Here you lack evidence of a risk of injuring someone because of a relatively minor failure. A non-evidence-relative conception of negligence, if applied consistently, would mean you commit the offence of dangerous driving. Your driving is dangerous to the student, and this would be obvious to careful and competent driver, because they would have checked the tyres and noticed the student. But convicting you of dangerous driving looks out of place; there would be a mismatch between your culpability and the seriousness of the offence. It also does not look like there is the requisite connection between you and the relevant risk - i.e. the risk of injuring someone - such that the badness of the risk speaks badly of you. So we should also prefer an evidence-relative negligence assessment in relation to this offence.

I have had to come up with a somewhat fanciful case to illustrate how the kind of mismatch I have been highlighting could occur with dangerous driving. I do not think that any real-life prosecutors or juries would judge in such a case that it would have been obvious to a careful and competent driver that your driving would dangerous. But the question is why. I would suggest that it is because our assessments of obviousness are implicitly relativized to the defendant's evidence, a relativization only made explicit with manslaughter following Rudling and Rose.

It is also worth noting that the kind of mismatch I have been highlighting will be much more likely to occur in relation to gross negligence manslaughter, and especially in the medical context, than in relation to other offences, because that context is one in which one can most frequently lack evidence of serious risks because of failures of evidence gathering. Such cases will also be much less likely to occur in the context of, for example, sexual offences. This is because sexual situations do not involve the same wide range of evidence gathering as the medical context. Instead, in relation to sexual offences, there is a limited set of relevant questions, namely those of consent and age, questions for which there are fairly standard, straightforward ways of answering, e.g. reading behavioural cues or asking if there is doubt. This contrasts with the medical context where there are a wide range of different evidence-gathering tasks a doctor can carry out, many of which could turn out to produce evidence of serious conditions that could not have been predicted in advance of the test, which makes cases of the structure of Rudling and Rose more likely. Nevertheless, such cases are theoretically possible in relation to any offence that can be committed negligently, given that all kinds of risk can be opaque to us. And this means that the same kinds of reasons I have given also support an evidence-relative test in other instances of negligence.

\section{WHY THIS UNDERMINES THE INDIRECT APPROACH TO CRIMINAL NEGLIGENCE}

With the evidence-relative conception defended, I can now explain why it undermines the indirect approach to criminal negligence. Essentially the problem with the indirect approach is that it cannot explain why criminal negligence assessments should be evidence-relative. And given that criminal negligence assessments should indeed be evidence-relative, this amounts to a reason to reject the indirect approach. 
The indirect approach, recall, claims that the culpability in criminal negligence is to be found in tracing the defendant's unawareness of the relevant risk back to prior culpable actions which led to that lack of awareness. This kind of approach cannot, I will now argue, explain why we would exclude failures of evidence gathering from assessments of negligence.

If the justification for the evidence-relative conception of criminal negligence that I have given is on the right lines (even vaguely), then failures of evidence gathering should be excluded because they are insecure grounds of culpability. Failures to recognise risks, given one's evidence, on the other hand, are not similarly insecure grounds of culpability, and so should be included in assessments of criminal negligence.

The problem for the indirect approach is that it cannot explain why failures of evidence gathering are insecure grounds of culpability. And it cannot explain why failures of evidence gathering are less secure grounds of culpability than failures to recognise risk given one's evidence. The reason why is because gathering evidence, recall, is just one kind of awareness-influencing action among others. The other kinds of awareness-influencing action we canvassed above were a) influencing our cognitive mechanisms, b) inculcating epistemic virtues and eliminating epistemic vices, and c) mental actions.

If the evidence-relative conception of negligence is correct, the defender of the indirect approach is going to have to argue that gathering evidence is a less secure ground of culpability than other kinds of awareness-influencing action. Because, given the indirect approach to negligence, it would only make sense to exclude failures of gathering evidence from consideration if gathering evidence were a less secure ground of culpability than other kinds of awareness-influencing action.

The trouble is that it looks difficult for the defender of the indirect approach to defend the claim that gathering evidence is a less secure ground of culpability than other kinds of awareness-influencing actions. The only obvious way for them to defend this claim would be to argue that other kinds of awareness-influencing actions are easier ways of influencing what one is aware of than gathering evidence. But this does not look like it is the case. If we look at the other kinds of awareness-influencing actions, they do not look like easier ways of influencing what we are aware of than gathering evidence. Influencing our cognitive mechanisms - doing things to, e.g., improve one's eyesight or reasoning ability - look like harder ways to influence what one is aware of than gathering evidence. The same is true of inculcating epistemic virtues and eliminating epistemic vices. Insofar as we can take steps to, e.g., try to be less gullible, it is really hard, and definitely harder than gathering evidence as a way of influencing what we are aware of.

Mental actions, such as directing one's attention, might initially seem like a more plausible avenue. In some respects, they do seem to be an easier way of influencing one's awareness than gathering evidence, in that they can be done "from the armchair". But I do not think appealing to mental actions can sustain the claim the defender of the indirect approach needs, namely that gathering evidence is a less secure ground of culpability. Firstly, mental actions like directing one's attention, despite the fact they can be done from the armchair, are not obviously an easier way to influence awareness than gathering evidence in any systematic way. Secondly, and more importantly, it is plausible that the vast majority of omissions to carry out the relevant mental action - e.g. failures to pay enough attention, to think before acting, or to remind oneself what one needs to do - are inadvertent omissions. And if they are inadvertent omissions, they will not be able to ground culpability for negligence in a way that helps deal with sceptical worries about 
criminal negligence liability. For this reason, I suspect that it is an illusion that mental actions could have much explanatory potential in this context.

Gathering evidence does not, therefore, look like a more difficult way of influencing what one is and is not aware of. So it does not seem that the indirect approach can explain why failures of gathering evidence are an insecure ground of culpability. And this means the indirect approach cannot account for why criminal negligence assessments should be evidence-relative.

Now one may object at this point that, because I appealed to wilful blindness in the previous section, I have allowed tracing to play some explanatory role in explaining negligence assessments. This is because wilful blindness involves a kind of tracing, as it is an instance of the culpability of one's ignorant conduct being explained by one's earlier culpable action of failing to investigate.

I grant that this involves tracing playing some role in some cases. But this does not undermine the key claim I am defending, because it is still the case that the tracing alone cannot explain our negligence assessments in the relevant cases of wilful blindness. In a case when someone is wilfully ignorant of a relevant fact, such as Laird's landlord who was wilfully blind to the fact that there was a gas leak, appealing to the doctrine of wilful blindness just involves considering one additional fact - the fact that there was a gas leak - alongside the rest of the landlord's possessed evidence. It does not involve considering all the evidence the landlord should have and could have had. And the indirect approach still has difficulty explaining why our assessment should be like this. Given that gathering evidence looks like an easier way of influencing what one is or is not aware of than other kinds of awareness-influencing action, if the indirect approach were correct, we should expect to include all the evidence the landlord should have and could have had in our negligence assessment. But we do not. So even if some appeal to tracing is made in cases which involve this kind of wilful blindness, they are still not cases where tracing alone can explain the agent's culpability.

We should therefore conclude that if the evidence-relative conception of criminal negligence is correct, as I have argued it is, we should reject the indirect approach to negligence. Criminal culpability for negligence is either direct, and does not need to be traced back to prior action, or holding people criminally responsible for negligence is unjustified.

With the objection to the indirect approach to negligence now completed, it will be helpful to reiterate how it differs from the typical objection to tracing accounts one finds in the literature. The typical objection involves putting forward putative cases of culpable negligence which cannot be traced back to culpable action, thus showing that tracing is insufficient to explain all instances of culpable ignorance. The objection I have made differs because I have shown that the indirect approach cannot why explain negligence assessments should be evidence-relative. As negligence assessments quite generally should be evidence-relative, this means that tracing is insufficient to explain negligence assessments quite generally. In other words, tracing is insufficient to explain any instance of culpable negligence. There are no "tracing cases" of negligence, if by this we mean cases of culpable negligence that can be explained by tracing alone.

\section{CONCLUDING THOUGHTS: HOW FAR TO GENERALISE?}

I mentioned above that an indirect approach to criminal negligence is an instance of the more general category of an indirect approach to inadvertent culpable ignorance. If the 
arguments I have made in this paper are correct, what should be said about the more general question in moral philosophy of whether tracing should play a role in explaining moral responsibility for inadvertent culpable ignorance?

There are two things to say here. Firstly, while criminal responsibility differs in important ways from moral responsibility, the arguments I have given also provide reasons to reject indirect approaches to understanding our moral responsibility for typical cases of inadvertent risk-taking and unwitting omissions. This is because cases of the structure of Rudling and Rose plausibly have the same implications with regards to moral blameworthiness as they do with criminal culpability. These cases showed that we must only take into account a defendant's possessed evidence to avoid mismatches between a defendant's degree of criminal culpability and the severity of what they are held responsible for. They also plausibly show that we must only take into account an agent's possessed evidence when assessing their blameworthiness for their inadvertent risktaking and unwitting omissions so that we avoid a mismatch between an agent's blameworthiness and what we are blaming them for. Even if we blame the defendant's in Rudling and Rose to some degree, it looks inappropriate to blame them for causing death. So moral blameworthiness, just like criminal culpability, should be assessed in an evidence-relative fashion. And given that an indirect approach could not explain this in the criminal case, it will not be able to explain it in the moral case either. So an indirect approach to moral responsibility for inadvertent risk-taking and unwitting omissions should also be rejected.

The second thing to note, though, is that what I have said does not have implications for appeals to tracing in understanding some instances of culpable ignorance. Specifically, it does not have implications for appeals to tracing to understand cases of self-induced intoxication (or other cases of self-induced incapacity). For all I have said, tracing could play a role in understanding such cases. However, while I cannot argue for this claim here, it is somewhat unclear whether tracing provides a good explanation of such cases. Choosing to get drunk, given getting drunk is often harmless, does not itself look sufficiently culpable or blameworthy to get us on the hook for whatever mischief we get up to while drunk. ${ }^{55}$ But even if this is wrong, and tracing can play a role in understanding cases of self-induced incapacity, it still cannot explain criminal or moral responsibility for negligence.

\footnotetext{
${ }^{55}$ See S. Dimock, "Please Drink Responsibly: Can the Responsibility of Intoxicated Offenders Be Justified by the Tracing Principle?" in N. A. Vincent, I. van de Poel, J. van den Hoven (eds.), Moral Responsibility: Beyond Free Will and Determinism (Dordrecht 2011); F. Stark, “"Prior Fault”” [2014] C.L.J. 8.
} 